OPEN ACCESS

Edited by:

Giuseppe Vizzielli,

Agostino Gemelli University

Polyclinic, Italy

Reviewed by:

Valerio Gallotta,

Agostino Gemelli University

Polyclinic, Italy

Giorgio Bogani,

Istituto Nazionale dei Tumori

(IRCCS), Italy

*Correspondence: Dongyan Cao

caodongyan@pumch.cn

Jie Yang

yangjie@pumch.cn

Specialty section:

This article was submitted to

Women's Cancer,

a section of the journal

Frontiers in Oncology

Received: 26 August 2019 Accepted: 07 October 2019 Published: 30 October 2019

Citation:

Yuan Z, Cao D, Yang J, Yu M, Shen K, Yang J, Zhang Y and Zhou H (2019) Laparoscopic vs. Open Abdominal Radical Hysterectomy for Cervical Cancer: A Single-Institution, Propensity Score Matching Study in China. Front. Oncol. 9:1107. doi: 10.3389/fonc.2019.01107

\section{Laparoscopic vs. Open Abdominal Radical Hysterectomy for Cervical Cancer: A Single-Institution, Propensity Score Matching Study in China}

\author{
Zhen Yuan, Dongyan Cao*, Jie Yang *, Mei Yu, Keng Shen, Jiaxin Yang, Ying Zhang and \\ Huimei Zhou
}

Department of Obstetrics and Gynecology, Peking Union Medical College Hospital, Peking Union Medical College, Chinese Academy of Medical Sciences, Beijing, China

Study Objective: To compare the surgical and oncologic outcomes between open abdomen radical hysterectomy $(\mathrm{ARH})$ and laparoscopic radical hysterectomy $(\mathrm{LRH})$ for cervical cancer.

Methods: Retrospective observational study with propensity score matching was used to ensure balanced groups for $\mathrm{ARH}$ and $\mathrm{LRH}$. One-hundred-and-ninety-eight women with cervical cancer, 99 treated using ARH and 99 using LRH, between January 2012 and December 2014. Outcomes included disease-free survival (DFS), overall survival (OS), intra-operative factors, post-operator recovery, urinary retention, and adverse events. Moreover, the inverse probability of the treatment weighting (IPTW) method was also used.

Main Results: Compared with $\mathrm{ARH}, \mathrm{LRH}$ was associated with a lower volume of blood loss $(P<0.001)$ and transfusion rate $(P<0.001)$, with a broader resection of the parametrium $(P<0.001)$. Post-operatively, the time to first flatus was shorter for $\mathrm{LRH}$ than $\mathrm{ARH}(P<0.001)$ but the rate of urinary retention was higher for $\mathrm{LRH}(22.2 \%)$ than $\mathrm{ARH}(8.1 \% ; P=0.009)$. DFS and OS were similar between groups. By IPTW, laparoscopy was also not associated with poorer survival in terms of DFS (HR 1.52, Cl 0.799-2.891, $P=0.202)$ or OS (HR 0.942, HR 0.425-2.09, $P=0.883)$.

Conclusion: Compared with $\mathrm{ARH}, \mathrm{LRH}$ provided better intra-operative and post-operative outcomes, with no significant difference in oncologic outcomes and survival. Urinary retention remains a clinical issue to improve with $\mathrm{LRH}$. The technology of $\mathrm{LRH}$ has been improved in China to address the inconsistent results of oncologic outcomes in previous studies. Whether these improvements could be effective needs to be investigated in the future.

Keywords: cervical cancer, laparoscopy, oncologic outcomes, open abdominal surgery, surgical outcomes 


\section{INTRODUCTION}

Recently, the unexpected result of a phase III prospective trial has brought a great debate within the academic arena (1). In this trial, minimally invasive radical hysterectomy was associated with a lower rate of disease-free survival (DFS) at 3-years post-surgery [91.2 vs. $97.1 \%$, respectively; hazard ratio (HR), 3.74 , with a $95 \%$ confidence interval (CI) of 1.63-8.58], and a decrease in overall survival (OS) at 3-years post-surgery (93.8 vs. $99.0 \%$, respectively; HR 6.00 and $95 \%$ CI, 1.77-20.30). Therefore, this trial provided evidence of poorer outcomes for minimally invasive radical hysterectomy than ARH, among women with early-stage cervical cancer.

This finding is not consistent with previously reported findings. In fact, previous studies reported on the therapeutic equivalency between MIRH and ARH, with MIRH providing additional benefits of a shorter duration in hospital stay and more rapid patient recovery $(2-4)$.

We do recognize that surgical skills and techniques vary between surgeons, and particularly between hospitals, therefore, our aim was to compare the rate of surgery- associated complications and survival between laparoscopic radical hysterectomy (LRH), which is a commonly used minimally invasive approach, and ARH at our institution.

\section{MATERIALS AND METHODS}

This study was approved by the Peking Union Medical College Hospital Ethics Review Board. Preoperatively, all patients provided written informed consent for data collection for research purposes. The data set was kept anonymous in order to protect patient privacy.

Inclusion criteria were as follows: surgery performed between January 2012 and December 2014; radical hysterectomy with lymphadenectomy; histological confirmation of squamous carcinoma, adenocarcinoma, or adenosquamous carcinoma; and regular follow-up. Patients with rare histological types of cancer and those lost to follow-up were excluded.

A radical hysterectomy includes the removal of the uterus as far as possible from the uterosacral ligaments, resection of the parameter as near as to the pelvic wall as possible, ligation of uterine vessels at the origin, and removal of $1 / 3$ of the upper vagina (5).

Two experienced gynecological oncologists determined the clinical stage of each case, according to the International Federation of Gynecology and Obstetrics (FIGO) 2009 guidelines. Histologic diagnosis was confirmed by at least two pathologists. The following information was collected from the medical records for analysis: age, body mass index (BMI), squamous cell carcinoma antigen (SCCAg) before the initial treatment, histological type, clinical stage, surgery-related complications, treatment modality, adjuvant therapy, and outcomes. According to Common Terminology Criteria for Adverse Events (v4.0 CTCAE), the adverse events with grade $\geq 3$ were recorded in our analysis. In this study, when the urinary catheter was removed postoperatively for the first time, a residual urine volume $\geq 100 \mathrm{ml}$ was defined as urinary retention.

\section{Statistical Analysis}

Propensity score matching was used to select patients, improving the quality of the results reported. Propensity-matched comparisons attempt to estimate the effect of a treatment, by accounting for possible factors that predict receiving the treatment, thus reducing possible selection biases. The following matching factors were used in our study: age, tumor size, stage, histologic type, lymph node metastasis, parametrium invasion, and surgical margin status. Patients undergoing LRH were matched 1:1 to patients selected to a cohort of women undergoing ARH, using a caliper width of $\leq 0.02$ standard deviations of the logit odds of the estimated propensity score. Moreover, the inverse probability of the treatment weighting (IPTW) method was also used (6), to capture information from patients who otherwise would be discarded by 1:1 matching.

Categorical variables are summarized in frequency tables, whereas continuous variables are presented as a mean \pm standard deviation or median (25th percentile-75th percentile), as appropriate for the data distribution. Frequency distributions were compared using the chi-squared tests by Fisher's exact test, as appropriate, with mean values compared using a $t$ test and median values using a non-parametric test.

DFS was calculated from the date of surgery to the date of first recurrence or last follow-up in patients and overall survival (OS) as the date of death or last contact. All of the follow-up information was censored following March 1, 2019. Survival curves were calculated using the Kaplan-Meier method and compared using the log-rank test. The data were analyzed using SPSS (version 23, IBM, Armonk, NY), Prism 7 (GraphPad Software, San Diego, CA) and RStudio (Version 1.1.463). A $p$ value $<0.05$ was considered statistically significant, using the two-tailed hypothesis.

\section{RESULTS}

The flowchart of patient selection is shown in Figure 1. After screening and matching, 99 patients were included in each of the ARH and LRH groups. The baseline clinical characteristics of the patients forming our study group are presented in Table $\mathbf{1}$.

Table 2 shows the postoperative pathological high-risk and intermediate-risk factor information for the two groups. Patients, with positive pelvic nodes, positive surgical margin, and/or positive parametrium, are considered to have a highrisk disease (7). Owing to the application of a propensitymatching algorithm, baseline characteristics and high risks were similar between groups. The "Sedlis Criteria" considers stromal invasion, lymphatic space involvement and primary tumor size to be intermediate risk factors (8). Regarding intermediate risk factors, there was no significant difference between the two groups. Regarding the adjuvant treatment, which includes neoadjuvant chemotherapy, adjuvant chemotherapy, and adjuvant radiation, the proportion of patients in two groups was not significantly different.

Table 3 summarizes surgery-related and oncological outcomes for both groups. Regarding intraoperative outcomes, the mean volume of blood loss was significantly lower in LRH 


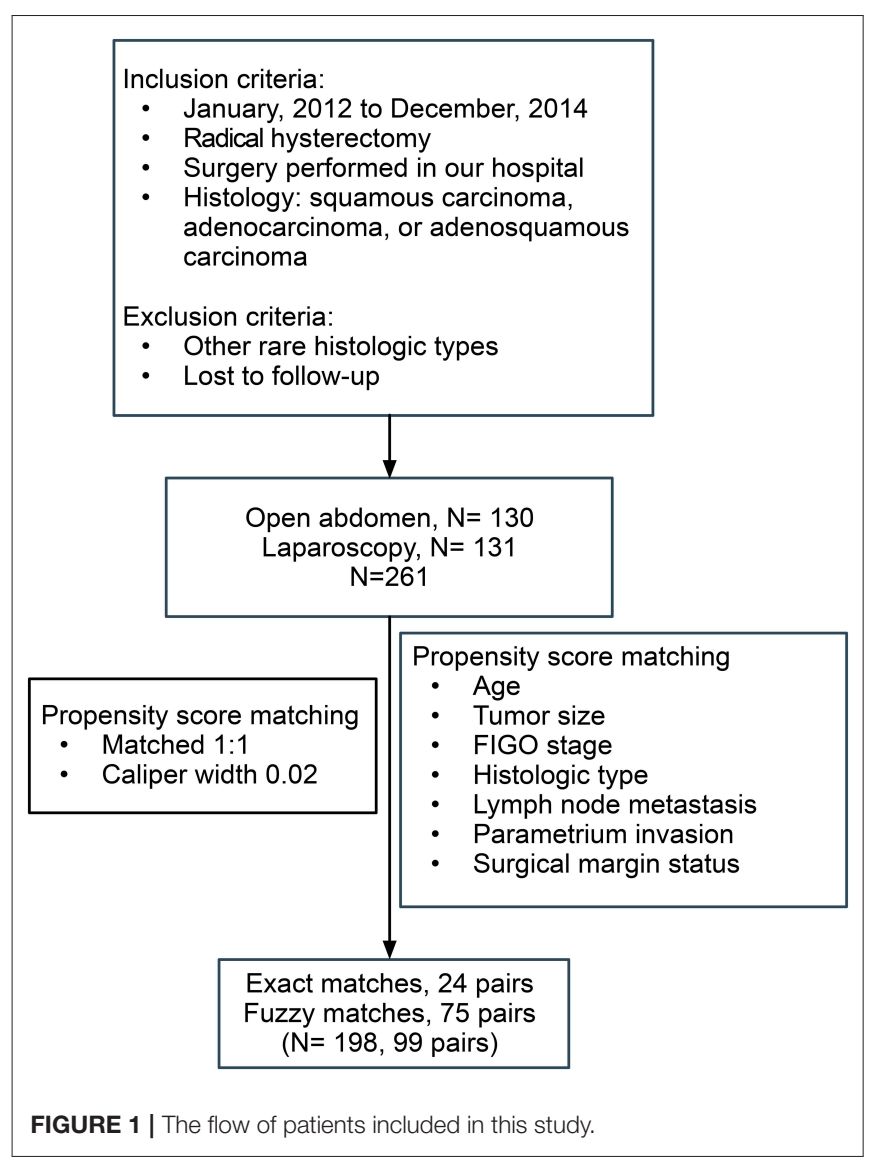

$(200 \mathrm{~mL})$ than ARH $(400.00 \mathrm{ml} ; P<0.001$; Figure 2) with the transfusion rate also being lower for $\mathrm{LRH}(1.0 \%)$ than $\mathrm{ARH}$ (20.2\%; $P<0.001$; Figure 2). The resected parametrium in LRH was broader in LRH than ARH $(P<0.001$; Figure 2). The median operative time, and the number of resected lymph nodes showed no significant difference between the two groups ( $P=0.377$ and 0.850 , respectively). In terms of postoperative outcomes, the first aerofluxus time in the LRH (2 days) group was shorter ( 3 days) than that in the ARH group $(P<0.001$; Figure 2). Time to removal of the first urinary catheter after surgery was not different between the two groups $(P=0.189)$, although the rate of urinary retention was higher in the LRH (22.2\%) than ARH (8.1\%) group ( $P=0.009$; Figure 2).

There was no difference between the two groups in terms of length of hospital stay, rate of unexpected second hospitalization and rate of unexpected second surgery rate $(P=0.224,0.445$, and 0.375 , respectively). The detailed information of surgeryassociated complications (grade $\geq 3$ ) is presented in Table 4 . Overall, 19 adverse events were associated with LRH and 22 with $\mathrm{ARH}$, over a period of 30 days after surgery, which was not significantly different between the two groups $(P=0.726)$. In the time period after 30 days, five adverse events were noted in the LRH group and two in the ARH group, again this difference not being significant $(P=0.445)$.

The median follow-up time of patients was 69 months in the ARH group and 59 in the LRH group. The DFS and OS curves,
TABLE 1 | Baseline clinical characteristics of the patients. Data are presented as number $(\%)$, mean $( \pm \mathrm{SD})$ or median (25th percentiles- 75th percentiles).

\begin{tabular}{|c|c|c|c|}
\hline & $\begin{array}{l}\text { Open abdomen } \\
\qquad(N=99)\end{array}$ & $\begin{array}{l}\text { Laparoscopy } \\
\qquad(n=99)\end{array}$ & $P$ value \\
\hline Age (years) & $44.56 \pm 7.60$ & $43.58 \pm 8.86$ & 0.405 \\
\hline BMl $\left(\mathrm{kg} / \mathrm{m}^{2}\right)$ & $24.56 \pm 1.50$ & $24.36 \pm 2.41$ & 0.479 \\
\hline Previous abdominal surgery, $N(\%)$ & $37(37.4 \%)$ & $40(40.4 \%)$ & \\
\hline SCCAg (ng/mL) & $\begin{array}{c}1.20 \\
(0.70-2.90)\end{array}$ & $\begin{array}{c}1.20 \\
(0.60-2.70)\end{array}$ & 0.549 \\
\hline CA125 (U/ml) & $\begin{array}{c}22.10 \\
(10.10-27.83)\end{array}$ & $\begin{array}{c}16.50 \\
(12.65-19.75)\end{array}$ & 0.586 \\
\hline \multicolumn{4}{|l|}{ PATHOLOGICAL TYPE } \\
\hline Squamous cell cancer, $N(\%)$ & 82 (82.8\%) & 82 (82.8\%) & 1.000 \\
\hline Adenocarcinoma, $N(\%)$ & $13(13.1 \%)$ & $14(14.1 \%)$ & 1.000 \\
\hline Adenosquamous cancer, $N(\%)$ & $4(4.1 \%)$ & $3(3.1 \%)$ & 1.000 \\
\hline \multicolumn{4}{|l|}{ FIGO STAGE } \\
\hline IA2-IB1, N (\%) & 72 (72.7\%) & $73(73.7 \%)$ & 1.000 \\
\hline IB2-IIA2, N (\%) & $27(27.3 \%)$ & $26(26.3 \%)$ & 1.000 \\
\hline Tumor size & $\begin{array}{c}3.00 \\
(1.30-4.00)\end{array}$ & $\begin{array}{c}2.50 \\
(1.00-4.00)\end{array}$ & 0.704 \\
\hline Patients with tumor size $>2 \mathrm{~cm}$, & 53 (53.5\%) & 50 (50.5\%) & 0.776 \\
\hline
\end{tabular}

$N(\%)$

SD, standard deviation; BMI, body mass index; SCCAg, squamous cell carcinoma antigen; CA125, serum cancer antigen 125; FIGO, International Federation of Gynecology and Obstetrics.

TABLE 2 | Pathological high-risk and intermediate-risk factors.

\begin{tabular}{|c|c|c|c|}
\hline & $\begin{array}{l}\text { Open abdomen } \\
\qquad(N=99)\end{array}$ & $\begin{array}{l}\text { Laparoscopy } \\
\qquad(n=99)\end{array}$ & $P$ value \\
\hline Pelvic lymph node metastasis, $N(\%)$ & $10(10.1 \%)$ & $11(11.1 \%)$ & 1.000 \\
\hline Parametrium invasion, N (\%) & $2(2.0 \%)$ & $0(0.0 \%)$ & 0.497 \\
\hline Vaginal cuff invasion, $N(\%)$ & $3(3.0 \%)$ & $1(1.0 \%)$ & 0.621 \\
\hline Deep myometrial invasion, $N(\%)$ & $43(43.4 \%)$ & $37(37.4 \%)$ & 0.469 \\
\hline Lymphovascular space invasion, N (\%) & 34 (34.3\%) & $23(23.2 \%)$ & 0.116 \\
\hline Neoadjuvant chemotherapy, N (\%) & $20(20.2 \%)$ & $20(20.2 \%)$ & 1.000 \\
\hline TP & $17(85.0 \%)$ & $16(80.0 \%)$ & $>0.999$ \\
\hline Others & $3(15.0 \%)$ & $4(20.0 \%)$ & $>0.999$ \\
\hline Adjuvant chemotherapy, N (\%) & $22(22.2 \%)$ & $21(21.2 \%)$ & 1.000 \\
\hline TP & $18(81.8 \%)$ & $19(90.5 \%)$ & 0.705 \\
\hline Others & $4(18.2 \%)$ & $2(9.5 \%)$ & 0.705 \\
\hline Adjuvant radiation, $N(\%)$ & $64(64.6 \%)$ & $50(50.5 \%)$ & 0.061 \\
\hline $\begin{array}{l}\text { Concurrent DDP-based } \\
\text { chemotherapy }\end{array}$ & 40 (62.5\%) & 27 (54.0\%) & 0.470 \\
\hline Others & 24 (37.5\%) & 23 (46.0\%) & 0.470 \\
\hline
\end{tabular}

TP, paclitaxel and cisplatin; DDP, cisplatin.

shown in Figure 3, were not significantly different between the two groups ( $P=0.222$ and 0.704 , respectively). The rates of DFS at 3-years in ARH and LRH were 96.0 and $92.0 \%$, respectively. And the rates of OS at 3-year in ARH and LRH were 97.0 and 96.0\%, respectively. Moreover, by IPWT, laparoscopy was also not associated with poorer survival in terms of DFS (HR 1.52, CI $0.799-2.891, P=0.202$ ) or OS (HR 0.942, HR 0.425-2.09, $P$ $=0.883$ ). 
TABLE 3 | Surgery-related and oncological outcomes of the patients.

\begin{tabular}{|c|c|c|c|}
\hline & $\begin{array}{l}\text { Open abdomen } \\
\qquad(N=99)\end{array}$ & $\begin{array}{l}\text { Laparoscopy } \\
\qquad(n=99)\end{array}$ & $P$ value \\
\hline Operating time (min) & $\begin{array}{c}165 \\
(150.00-180.00)\end{array}$ & $\begin{array}{c}180 \\
(160.00-200.00)\end{array}$ & 0.377 \\
\hline $\begin{array}{l}\text { The number of resected lymph } \\
\text { nodes }\end{array}$ & $\begin{array}{c}27 \\
(20.00-34.00)\end{array}$ & $\begin{array}{c}26 \\
(22.00-34.75)\end{array}$ & 0.850 \\
\hline Blood loss (ml) & $\begin{array}{c}400.00 \\
(300.00-600.00)\end{array}$ & $\begin{array}{c}200.00 \\
(150.00-300.00)\end{array}$ & $<0.001$ \\
\hline Transfusion, N (\%) & $20(20.2 \%)$ & $1(1.0 \%)$ & $<0.001$ \\
\hline $\begin{array}{l}\text { Severe complications in } 30 \\
\text { postoperative days, } N(\%)\end{array}$ & 19 (19.2\%) & $22(22.2 \%)$ & 0.726 \\
\hline $\begin{array}{l}\text { Severe complications after } 30 \\
\text { postoperative days, } N(\%)\end{array}$ & $2(2.0 \%)$ & $5(5.1 \%)$ & 0.445 \\
\hline Unexpected second surgery, $N(\%)$ & $3(3.0 \%)$ & $4(4.0 \%)$ & 1.000 \\
\hline $\begin{array}{l}\text { Unexpected second hospitalization, } \\
N(\%)\end{array}$ & $2(2.0 \%)$ & $5(5.1 \%)$ & 0.445 \\
\hline $\begin{array}{l}\text { Postoperative first aerofluxus time } \\
\text { (days) }\end{array}$ & $\begin{array}{c}3.00 \\
(2.00-3.00)\end{array}$ & $\begin{array}{c}2.00 \\
(2.00-3.00)\end{array}$ & $<0.001$ \\
\hline Length of hospital stay(days) & $\begin{array}{c}11.00 \\
(9.00-17.00)\end{array}$ & $\begin{array}{c}10.00 \\
(8.00-16.00)\end{array}$ & 0.224 \\
\hline $\begin{array}{l}\text { Postoperative first uterine catheter } \\
\text { removal time (days) }\end{array}$ & $\begin{array}{c}14.00 \\
(14.00-14.00)\end{array}$ & $\begin{array}{c}14.00 \\
(11.50-14.00)\end{array}$ & 0.189 \\
\hline Urine retention, $N(\%)$ & $8(8.1 \%)$ & 22 (22.2\%) & 0.009 \\
\hline Relapse, $N(\%)$ & $4(4.0 \%)$ & $8(8.1 \%)$ & 0.375 \\
\hline \multicolumn{4}{|l|}{ RELAPSE SITE } \\
\hline Pelvic cavity & 2 (50.0\%) & $5(62.5 \%)$ & $>0.999$ \\
\hline Distance & $2(50.0 \%)$ & $3(37.5 \%)$ & $>0.999$ \\
\hline Mortality, N (\%) & $3(3.0 \%)$ & $4(4.0 \%)$ & 1.000 \\
\hline Follow-up time (months) & $\begin{array}{c}69.00 \\
(61.00-76.00)\end{array}$ & $\begin{array}{c}59.00 \\
(53.00-67.00)\end{array}$ & \\
\hline
\end{tabular}

\section{A REVIEW}

A literature search was performed in PubMed, Embase and Web of Science, using the following search words: "uterine cervical neoplasm," "laparotomy," "laparoscopy," and "minimally invasive surgical procedures." The search was limited to publications between January 2014 and May 2019. Studies included in our review had to meet all of the following criteria: (a) uterine cervical cancer; (b) radical hysterectomy and lymphadenectomy; (c) data including the comparison of laparotomy and laparoscopy; (d) date including oncologic survival outcomes; (e) studies published in English. In total 13 articles were included $(1,9-20)$ with details shown in Supplementary Table 1.

\section{DISCUSSION}

Our findings provide evidence of comparable or better surgical and oncologic outcomes for LRH than ARH, with the exception of a higher rate of urinary retention after LRH. We note the details of our study design that strengthen our evidence. First, acknowledging that these outcomes will be influenced by surgeons' experience, particularly between institutions (2123). We conducted a single site study, with all procedures performed by experienced oncologic gynecological surgeons.
Also, considering the learning curve required for laparoscopic procedures (21), we selected patients who underwent LRH or ARH after January 2012, when laparoscopic technique was well-established in our center, thus excluding effects of inexperience on LRH outcome. Lastly, we also used propensity score matching (24) and IPWT to balance the two comparison groups on all major factors known to influence outcomes. To the best of our knowledge, this is the largest single site study, with propensity score matching and IPWT, to have compared LRH to ARH in terms of surgical and oncologic outcomes.

Our findings of better intra-operative outcomes for LRH than ARH are consistent with previous studies $(10,13,25)$, including a smaller volume of blood loss and a lower transfusion rate. These findings reflect the better ability to identify small vessels under the magnification provided by an optical system on the laparoscope, as well as the use of the argon-beam coagulator during surgery (26). Our finding of a shorter time to first flatus in the LRH than ARH group, indicative of a relatively shorter postoperative recovery, is also consistent with previous studies $(27,28)$.

Gynecological surgery for malignancy is associated with a high incidence rate of pelvic disorder (29). Urinary retention is one of symptoms related to urinary dysfunction associated with pelvic floor disorder, which notably occurs with cervical cancer surgery (30). Urinary retention leads to delay in ultimate removal of the urinary catheter, which increases the risk of urinary tract infection and negatively impacts the post-operative quality of life (30). It is important to note, however, that the definition of urinary retention varies across studies. Using the definition of a post-void residual urine volume $>100 \mathrm{ml}$, Ceccaroni et al. reported a prevalence rate of urinary retention of $39 \%, 28$ days after laparoscopic type III hysterectomy (31). Using a similar definition, the rate of urinary retention in LRH was $22.2 \%$. Moreover, the rate in LRH was significantly higher than the $8.1 \%$ rate in the ARH group. We note that our finding was not consistent with those of previous studies $(27,32)$. One previous study reported a significantly longer duration of catheterization than after open laparoscopic surgery (27). A longer duration of catheterization after open surgery was similarly reported in another study, where urinary retention was defined by an absence of voiding $>6 \mathrm{~h}$ after Foley catheter removal, with a concomitant estimation of bladder filling $>300 \mathrm{ml}$ on ultrasound examination (32). Differences in definition of urinary retention and the broader resection parameter LRH may be the reason why our rate of urinary retention was higher for LRH than ARH.

Differences in oncological outcomes between LRH and ARH are essential to consider and opinions vary from different studies $(1,9-20)$. After the consternation brought to light by the study of Ramirez et al. (1), a prospective randomized international phase III trial, gynecologists began to think how do we proceed in the face of these data (33). More than $85 \%$ of cervical cancer cases occur in developing countries (34). China as a developing country has multiple cases of patients with cervical cancer. How do gynecologists in China proceed in the face of these data? 

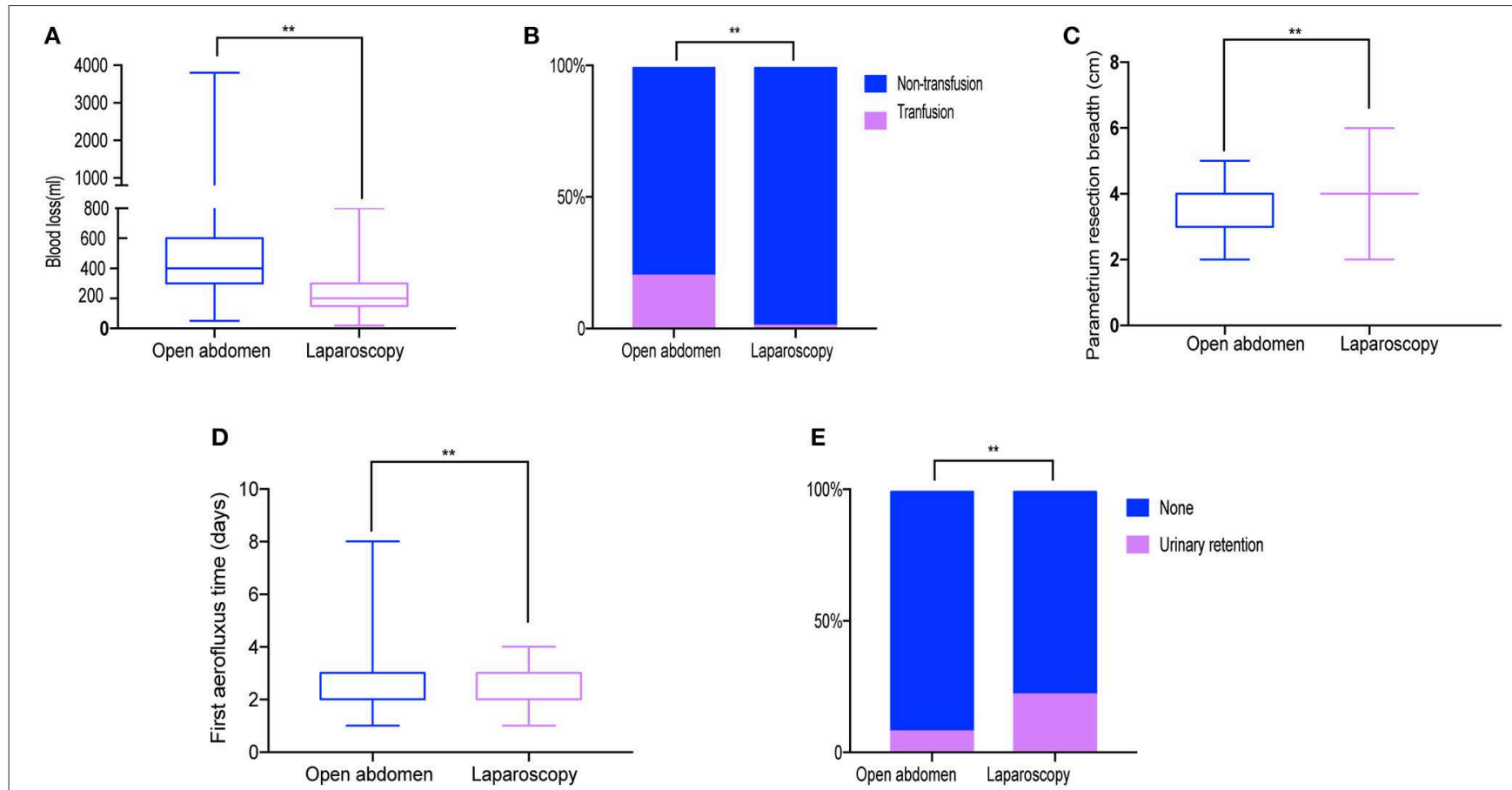

FIGURE 2 | Surgery-related outcomes. (A) Blood loss. (B) Transfusion rate (C) Resected parametrium breadth. (D) Aerofluxus time. (E) Urinary retention rate. ${ }^{\star \star} P<0.01$.

TABLE 4 | The detail information of surgery-related complications in two groups.

\begin{tabular}{lcc}
\hline & $\begin{array}{c}\text { Open abdomen } \\
(\boldsymbol{n}=\mathbf{9 9 )}\end{array}$ & $\begin{array}{c}\text { Laparoscopy } \\
(\boldsymbol{n}=\mathbf{9 9 )}\end{array}$ \\
\hline Severe complications in 30 & 19 & 22 \\
postoperative days, $N$ (\%) & $(19.2 \%)$ & $(22.2 \%)$ \\
Vesicovaginal fistula & 0 & 2 \\
Ureteral fistula & 1 & 1 \\
Intestinal obstruction & 5 & 0 \\
Poor wound healing & 6 & 1 \\
Pelvic lymphocyst (Puncture needed) & 1 & 1 \\
Fever/Infection & 6 & 15 \\
Deep vein thrombosis & 0 & 1 \\
Rectovaginal fistula & 0 & 1 \\
Severe complications after 30 & 2 & 5 \\
postoperative days, $N$ (\%) & $(2.0 \%)$ & $(5.1 \%)$ \\
Hydronephrosis (Double J needed) & 2 & 4 \\
Urinary incontinence & 0 & 1 \\
\hline
\end{tabular}

First, we analyzed the results in our institution in our study, the rates of DFS at 3-years in ARH and LRH were 96.0 and $92.0 \%$, respectively and the rates of OS at 3-years in ARH and LRH were 97.0 and $96.0 \%$, respectively, which were comparable to that seen in the open abdomen group in the studies of Ramirez et al. (1) and those in the study of Martin-Hirsch et al. (33). No significant difference was found between the ARH group and LRH group in our study.

Second, as shown in Figure 4, technical expertise in China has evolved, moving away from using a uterine manipulator to a

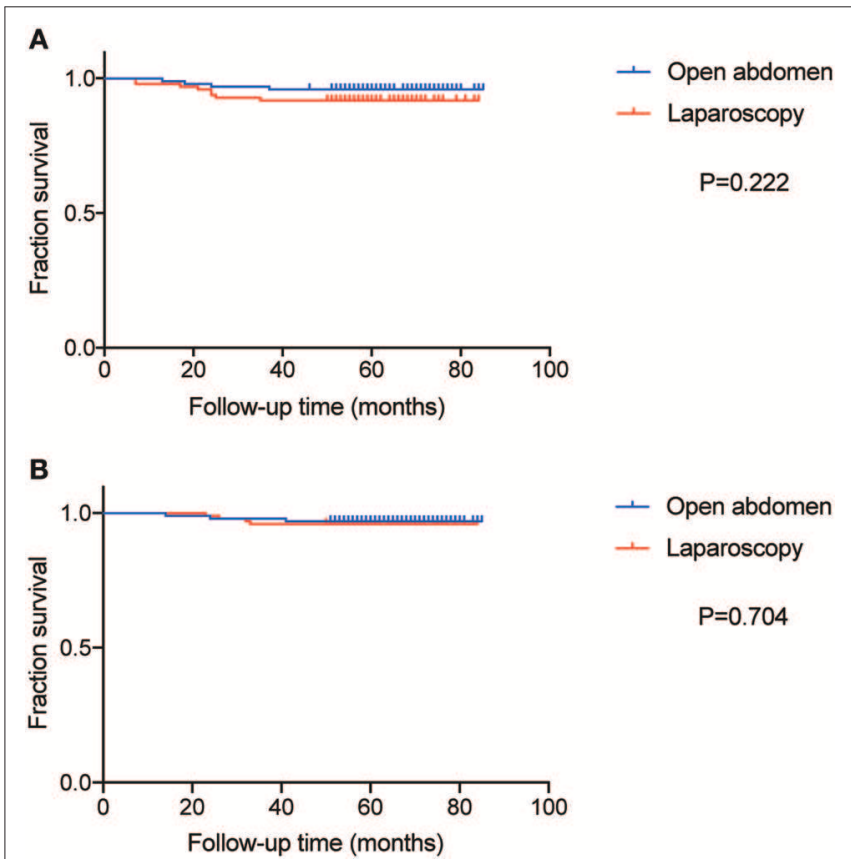

FIGURE 3 | The curve of Disease-free survival (DFS) and overall survival (OS). (A) The curve of DFS. (B) The curve of OS.

hitch technique (35). Moreover, before creating an incision in the vaginal wall, vaginal cerclage is now performed to avoid tumor exposure to the abdominal cavity, adhering to the non-tumor 


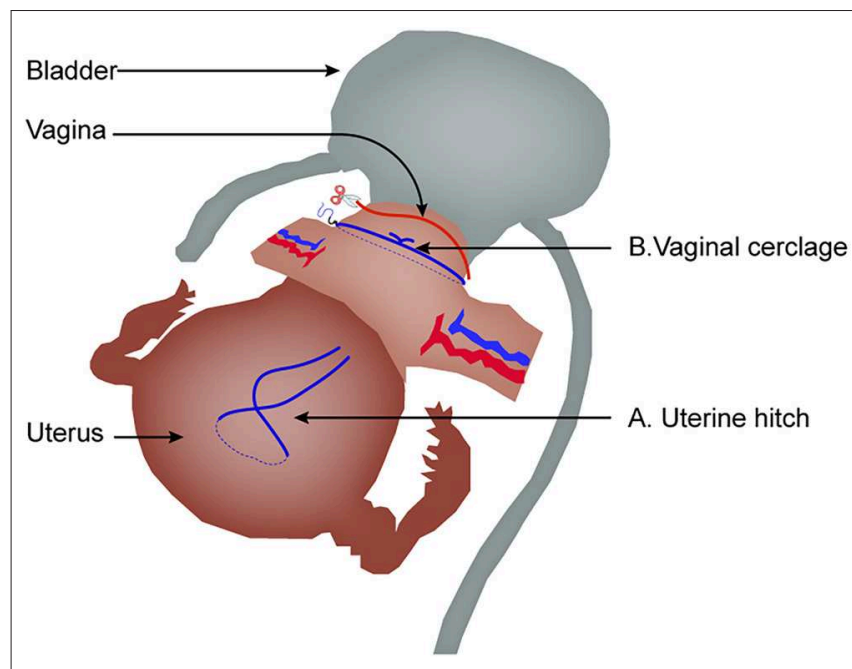

FIGURE 4 | The evolved expertise in laparoscopic radical hysterectomy. (A) Uterine hitch technique replacing uterine manipulator. (B) Vaginal cerclage before creating an incision in the vaginal wall.

principle. Whether the evolving expertise could be beneficial to oncological outcome or not remains to be investigated.

In conclusion, in our study, LRH was associated with less intra-operative complications and better postoperative recovery than ARH, with no significant difference in oncologic outcomes. As technological expertise with LRH continues to grow, future studies are needed to continue to monitor and evaluate outcomes.

\section{DATA AVAILABILITY STATEMENT}

All datasets generated for this study are included in the article/Supplementary Material.

\section{REFERENCES}

1. Ramirez PT, Frumovitz M, Pareja R, Lopez A, Vieira M, Ribeiro R, et al. Minimally invasive versus abdominal radical hysterectomy for cervical cancer. N Engl J Med. (2018) 379:1895-904. doi: 10.1056/NEJMoa1806395

2. Shazly SA, Murad MH, Dowdy SC, Gostout BS, Famuyide AO. Robotic radical hysterectomy in early stage cervical cancer: a systematic review and meta-analysis. Gynecol Oncol. (2015) 138:457-71. doi: 10.1016/j.ygyno.2015. 06.009

3. Nevis IF, Vali B, Higgins C, Dhalla I, Urbach D, Bernardini MQ. Robotassisted hysterectomy for endometrial and cervical cancers: a systematic review. J Robot Surg. (2017) 11:1-16. doi: 10.1007/s11701-016-0621-9

4. Cantrell LA, Mendivil A, Gehrig PA, Boggess JF. Survival outcomes for women undergoing type III robotic radical hysterectomy for cervical cancer: a 3-year experience. Gynecol Oncol. (2010) 117:260-5. doi: 10.1016/j.ygyno.2010.01.012

5. Marin F, Plesca M, Bordea CI, Moga MA, Blidaru A. Types of radical hysterectomies: from Thoma Ionescu and Wertheim to present day. J Med Life. (2014) 7:172-6.

6. Austin PC, Stuart EA. Moving towards best practice when using inverse probability of treatment weighting (IPTW) using the propensity score to estimate causal treatment effects in observational studies. Stat Med. (2015) 34:3661-79. doi: 10.1002/sim.6607

\section{ETHICS STATEMENT}

This study was approved by the Peking Union Medical College Hospital Ethics Review Board. Preoperatively, all patients provided written informed consent for data collection for research purposes.

\section{AUTHOR'S NOTE}

Compared with abdominal radical hysterectomy, laparoscopic radical hysterectomy provided better intra-operative and postoperative outcomes, with no significant difference in oncologic outcomes and survival.

\section{AUTHOR CONTRIBUTIONS}

All authors listed have made a substantial, direct and intellectual contribution to the work, and approved it for publication.

\section{FUNDING}

This study was funded by the National Natural Science Foundation of China (81572576 to KS) and CAMS Initiative for Innovative Medicine (CAMS-2017-12M-1-002 to KS).

\section{SUPPLEMENTARY MATERIAL}

The Supplementary Material for this article can be found online at: https://www.frontiersin.org/articles/10.3389/fonc. 2019.01107/full\#supplementary-material

7. Peters WA III, Liu PY, Barrett RJ II, Stock RJ, Monk BJ, Berek JS, et al. Concurrent chemotherapy and pelvic radiation therapy compared with pelvic radiation therapy alone as adjuvant therapy after radical surgery in highrisk early-stage cancer of the cervix. J Clin Oncol. (2000) 18:1606-13. doi: 10.1200/JCO.2000.18.8.1606

8. Sedlis A, Bundy BN, Rotman MZ, Lentz SS, Muderspach LI, Zaino RJ. A randomized trial of pelvic radiation therapy versus no further therapy in selected patients with stage IB carcinoma of the cervix after radical hysterectomy and pelvic lymphadenectomy: a Gynecologic Oncology Group Study. Gynecol. Oncol. (1999) 73:177-83. doi: 10.1006/gyno.1999.5387

9. Ratiu D, Luncescu C, Morgenstern B, Eichler C, Gruttner B, Ludwig S, et al. Comparison of minimally invasive surgery and abdominal surgery among patients with cervical cancer. Anticancer Res. (2019) 39:2661-4. doi: 10.21873/anticanres. 13390

10. Gil-Moreno A, Carbonell-Socias M, Salicrú S, Centeno-Mediavilla C, FrancoCamps S, Colas E, et al. Radical hysterectomy: efficacy and safety in the dawn of minimally invasive techniques. J Minim Invasive Gynecol. (2019) 26:492-500. doi: 10.1016/j.jmig.2018.06.007

11. Melamed A, Margul DJ, Chen L, Keating NL, del Carmen MG, Yang J, et al. Survival after minimally invasive radical hysterectomy for early-stage cervical cancer. N Engl J Med. (2018) 379:1905-14. doi: 10.1056/NEJMoa1804923

12. Corrado G, Vizza E, Legge F, Anchora LP, Sperduti I, Fagotti A, et al. Comparison of different surgical approaches for stage IB1 cervical cancer 
patients: a multi-institution study and a review of the literature. Int J Gynecol Cancer. (2018) 28:1020-8. doi: 10.1097/IGC.0000000000001254

13. Diver E, Hinchcliff E, Gockley A, Melamed A, Contrino L, Feldman S, et al. Minimally invasive radical hysterectomy for cervical cancer is associated with reduced morbidity and similar survival outcomes compared with laparotomy. J Minim Invasive Gynecol. (2017) 24:402-6. doi: 10.1016/j.jmig.2016.12.005

14. Laterza RM, Uccella S, Casarin J, Morosi C, Serati M, Koelbl H, et al. Recurrence of early stage cervical cancer after laparoscopic versus open radical surgery. Int J Gynecol Cancer. (2016) 26:547-52. doi: 10.1097/IGC.0000000000000627

15. Corrado G, Cutillo G, Saltari M, Mancini E, Sindico S, Vici P, et al. Surgical and oncological outcome of robotic surgery compared with laparoscopic and abdominal surgery in the management of locally advanced cervical cancer after neoadjuvant chemotherapy. Int J Gynecol Cancer. (2016) 26:539-46. doi: 10.1097/IGC.0000000000000646

16. Arispe C, Pomares AI, De Santiago J, Zapardiel I. Evolution of radical hysterectomy for cervical cancer along the last two decades: single institution experience. Chin J Cancer Res. (2016) 28:215-20. doi: $10.21147 /$ j.issn.1000-9604.2016.02.09

17. Xiao $M$, Zhang Z. Total laparoscopic versus laparotomic radical hysterectomy and lymphadenectomy in cervical cancer: an observational study of 13year experience. Medicine. (2015) 94:e1264. doi: 10.1097/MD.00000000000 01264

18. Bogani G, Cromi A, Serati M, Di Naro E, Casarin J, Pinelli C, et al. Improving standard of care through introduction of laparoscopy for the surgical management of gynecological malignancies. Int J Gynecol Cancer. (2015) 25:741-50. doi: 10.1097/IGC.0000000000000406

19. Toptas T, Simsek T. Total laparoscopic versus open radical hysterectomy in stage IA2-IB1 cervical cancer: disease recurrence and survival comparison. $J$ Laparoendosc Adv Surg Tech. (2014) 24:373-8. doi: 10.1089/lap.2013.0514

20. Chen $\mathrm{CH}$, Chiu LH, Chang CW, Yen YK, Huang YH, Liu WM. Comparing robotic surgery with conventional laparoscopy and laparotomy for cervical cancer management. Int J Gynecol Cancer. (2014) 24:1105-11. doi: 10.1097/IGC.0000000000000160

21. Tahmasbi Rad M, Wallwiener M, Rom J, Sohn C, Eichbaum M. Learning curve for laparoscopic staging of early and locally advanced cervical and endometrial cancer. Arch Gynecol Obstet. (2013) 288:635-42. doi: 10.1007/s00404-013-2787-y

22. McDonnell RM, Hollingworth JL, Chivers P, Cohen PA, Salfinger SG. Advanced training of gynecologic surgeons and incidence of intraoperative complications after total laparoscopic hysterectomy: a retrospective study of more than 2000 cases at a single institution. J Minim Invasive Gynecol. (2018) 25:810-5. doi: 10.1016/j.jmig.2017.12.005

23. Gallotta V, Conte C, Federico A, Vizzielli G, Gueli Alletti S, Tortorella $\mathrm{L}$, et al. Robotic versus laparoscopic radical hysterectomy in early cervical cancer: a case matched control study. Eur J Surg Oncol. (2018) 44:754-9. doi: 10.1016/j.ejso.2018.01.092

24. Jupiter DC. Propensity score matching: retrospective randomization? J Foot Ankle Surg. (2017) 56:417-20. doi: 10.1053/j.jfas.2017.01.013

25. Wang YZ, Deng L, Xu HC, Zhang Y, Liang ZQ. Laparoscopy versus laparotomy for the management of early stage cervical cancer. BMC Cancer. (2015) 15:928. doi: 10.1186/s12885-015-1818-4
26. Spirtos NM, Schlaerth JB, Kimball RE, Leiphart VM, Ballon SC. Laparoscopic radical hysterectomy (type III) with aortic and pelvic lymphadenectomy. Am J Obstet Gynecol. (1996) 174:1763-8. doi: 10.1016/S0002-9378(96) 70208-9

27. He HY, Yang ZJ, Zeng DY, Yao DS, Fan JT, Zhao RF, et al. Comparison of the short-term and long-term outcomes of laparoscopic surgery and open surgery for early-stage cervical cancer. Chin J Oncol. (2017) 39:458-66. doi: 10.3760/cma.j.issn.0253-3766.2017.06.011.

28. Park JY, Kim DY, Kim JH, Kim YM, Kim YT, Nam JH. Laparoscopic compared with open radical hysterectomy in obese women with early-stage cervical cancer. Obstet Gynecol. (2012) 119:1201-9. doi: 10.1097/AOG.0b013e318256ccc5

29. Neron M, Bastide S, Tayrac R, Masia F, Ferrer C, Labaki M, et al. Impact of gynecologic cancer on pelvic floor disorder symptoms and quality of life: an observational study. Sci Rep. (2019) 9:2250. doi: 10.1038/s41598-01938759-5

30. Ramaseshan AS, Felton J, Roque D, Rao G, Shipper AG, Sanses TVD. Pelvic floor disorders in women with gynecologic malignancies: a systematic review. Int Urogynecol J. (2018) 29:459-76. doi: 10.1007/s00192-0173467-4

31. Ceccaroni M, Roviglione G, Spagnolo E, Casadio P, Clarizia R, Peiretti $\mathrm{M}$, et al. Pelvic dysfunctions and quality of life after nerve-sparing radical hysterectomy: a multicenter comparative study. Anticancer Res. (2012) 32:581-8.

32. Uccella S, Laterza R, Ciravolo G, Volpi E, Franchi M, Zefiro F, et al. A comparison of urinary complications following total laparoscopic radical hysterectomy and laparoscopic pelvic lymphadenectomy to open abdominal surgery. Gynecol Oncol. (2007) 107(Suppl. 1):S147-9. doi: 10.1016/j.ygyno.2007.07.027

33. Martin-Hirsch P, Wood N, Whitham NL, Macdonald R, Kirwan J, Anagnostopoulos A, et al. Survival of women with early-stage cervical cancer in the UK treated with minimal access and open surgery. BJOG. (2019) 126:956-9. doi: 10.1111/1471-0528.15617

34. Torre LA, Bray F, Siegel RL, Ferlay J, Lortet-Tieulent J, Jemal A. Global cancer statistics, 2012. CA. (2015) 65:87-108. doi: 10.3322/caac. 21262

35. Puntambekar SP, Patil AM, Rayate NV, Puntambekar SS, Sathe RM, Kulkarni MA. A novel technique of uterine manipulation in laparoscopic pelvic oncosurgical procedures: "the uterine hitch technique". Minim Invasive Surg. (2010) 2010:836027. doi: 10.1155/2010/836027

Conflict of Interest: The authors declare that the research was conducted in the absence of any commercial or financial relationships that could be construed as a potential conflict of interest.

Copyright (c) 2019 Yuan, Cao, Yang, Yu, Shen, Yang, Zhang and Zhou. This is an open-access article distributed under the terms of the Creative Commons Attribution License (CC BY). The use, distribution or reproduction in other forums is permitted, provided the original author(s) and the copyright owner(s) are credited and that the original publication in this journal is cited, in accordance with accepted academic practice. No use, distribution or reproduction is permitted which does not comply with these terms. 